\title{
Condom Use and HIV-Related Behaviors in Portuguese Men who have Sex with Men: A Study of Sexual Behavior and Sexual Pleasure
}

\section{Henrique Pereira*}

Department of Psychology and Education, University of Beira Interior, Portugal \& Psychology \& Health Research Unit, ISPA-IU, Portugal

\begin{abstract}
Background: The purpose of this study is to assess the types of sexual behaviors among men who have sex with men (MSM), with and without a condom, and to assess the predictive relationship between sexual pleasure and risky sexual practices among MSM.

Methods: A total 304 MSM (Mean age $32.30, S D=11.28$ ) recruited through informal social networks and the Internet participated in this study. Most participants were single and self-identified as gay (70\%). Sexual pleasure was operationalized using one measure with 8 items (reliability analysis was good $\alpha=0.76$ ). Participants were asked to recall their sexual experiences and their sexual behaviors over the last two months.

Results: Only $7.2 \%$ of participants reported being HIV positive and approximately $26 \%$ reported not knowing their status. All participants indicated that they would feel higher levels of sexual pleasure if they were not using a condom during their sexual interaction, and all differences were statistically significant. Differences were also found between the following scenarios: a) having sex with or without a condom for receptive anal sex $(p=0.036)$, b) having sex with or without a condom for insertive anal sex $(p=0.012)$, and $c)$ having sex with or without a condom for oral sex $(p<0.001)$. Linear regression indicated that pleasure is a predictor of how many times a man was penetrated without a condom $(\beta=0.255 ; \mathrm{R} 2=0.084 ; p<0.05)$ and a predictor of how many times a man penetrated another man without a condom $(\beta=0.291 ; R 2=0.066 ; p<0.05)$.
\end{abstract}

Conclusion: Sexual pleasure needs to be prioritized in the development of condoms and other sexual safety measures as well as in the promotion of their use when working with HIV prevention among MSM.

Keywords: Men who have sex with men (MSM); HIV/AIDS; Pleasure; Risk behavior; Condoms; Portugal

\section{Introduction}

In Portugal there are an estimated 41,035 HIV-infected individuals [1], and a prevalence rate of 0.82 (ages 15-49), being this one of the highest rates in Western Europe [2]. In addition, $81.7 \%$ of the people diagnosed with HIV were men, and although the highest rate of HIV infection is through heterosexual unprotected $\operatorname{sex}(38 \%)$ and intravenous drug users who share unclean needles (44.7\%), approximately $12.4 \%$ of all infections were transmitted via homosexual and/or bisexual unprotected sex (these data refer to the cumulative percentage of HIV transmissions from 1983 to 2011) [1]. This is particularly important to mention given that this rate has doubled since 2001 among man who have sex with men (MSM) in Portugal, and these estimates only regard the notified cases, not considering the unreported cases. Therefore, MSM remain one of the most at risk groups for HIV transmission [3]. Despite these worrisome statistics, little systematic research has been conducted in Portugal on the psychosocial and contextual factors associated with unsafe sex among MSM, namely sexual pleasure.

Much of the literature on the psychosocial determinants of HIV infection focuses on the cognitive determinants related to HIV infection, such as information, beliefs or coping strategies, and not on emotional determinants, such as perceived pleasure associated with sexual practices $[4,5]$.

The decision to use condom with sexual partners as an effective tool to reduce the risk of risk of HIV infection by $80-95 \%$ [6-8] is complex, multifaceted, and may include factors such as sensationseeking, esoteric activities (i.e., gang bang as a bottom, water sports, fist fucking, SMor scatophilia), oral contact with sperm, and bare backing [9], or familiarity between sex partners, which has been associated with the likelihood to engage in unprotected anal intercourse with casual partners [10]. Thus, it is possible that a certain sexual culture may accentuate pleasure and adventurism instead of health and protection. Sex partying, for example, may occur on multiple sites and appears to be geared to the maximization of sexual pleasure, emphasizing the importance of 'intensity' [11]. Bauermeister et al. [12], for example, found a positive association between the decision to engage in bareback and unprotected receptive anal intercourse, number of partners, and having one or more sero discordant partners in the past 3 months. This may indicate that MSM might avoid using condoms in order to cope with psychosocial vulnerabilities and create intimacy with other MSM [13].

The broader context of contemporary HIV risk/harm reduction efforts, includes serosorting (seeking less risky partners), acts (strategic positioning), and negotiated safety. These may represent challenged that needs to be addressed by research since these factors are directly related to sexual pleasure. For example, Kelly et al. [14] found in their study with HIV sero-different couples that physical pleasure, love, commitment and a dislike of condoms within regular ongoing

${ }^{*}$ Corresponding author: Henrique Pereira, Department of Psychology and Education, University of Beira Interior, Portugal \& Psychology \& Health Research Unit, ISPA-IU, Portugal, Tel: 275329161 ext 4819; E-mail: hpereira@ubi.pt

Received January 30, 2014; Accepted March 24, 2014; Published March 30 2014

Citation: Pereira H (2014) Condom Use and HIV-Related Behaviors in Portuguese Men who have Sex with Men: A Study of Sexual Behavior and Sexual Pleasure. J AIDS Clin Res 5: 294. doi:10.4172/2155-6113.1000294

Copyright: (C) 2014 Pereira H . This is an open-access article distributed under the terms of the Creative Commons Attribution License, which permits unrestricted use, distribution, and reproduction in any medium, provided the original author and source are credited. 
relationships, shaped individuals' sense of biological risk so as to be able to have sex without condoms with less chance of HIV transmission.

The dynamics involved in unprotected and safe sex have changed over the last three decades. At the beginning of the AIDS epidemic, MSM experienced multiple deaths and were terrified by a new, mysterious, and untreatable disease. Today, younger MSM do not usually have this experience. They are, therefore, less afraid of HIV and may consider the strict use of condoms as more restrictive and denying of intimacy and pleasure, than older MSM [15].

According to Berhan and Berhan [5], out of 79736 men, aged 15-49 years, who had sexual intercourse in the previous 12 months, $35.7 \%$ reported to have higher-risk sex. In this study, the proportion of higher-risk sex was found to be positively correlated with an increased wealth index. In 24 countries, higher-risk sex was found to present a statistically significant association with men living in urban areas, educated (secondary education and above), and with a middle to high wealth index. Nearly in two-thirds of countries reported HIVprevalence, the proportion of HIV infection was highest among better educated, thus indicating that having access to information does not necessarily determine safer sexual behaviors.

Understanding situations that increase HIV risk among MSM requires consideration of the context in which risky behaviors occur. Relationships are one such context. Hoff et al. [16] found that positive relationship factors, such as attachment and intimacy, were associated with an increased likelihood of practicing unprotected anal intercourse with the primary partner. Meanwhile, $22 \%$ of the sample engaged in at least one episode of unprotected sex with an outside partner, half of whom were discordant or unknown HIV status outside partners. Another context is the internet. Negotiation of sex on the Internet shows that MSM are more likely to engage in sexual negotiation and sero status disclosure on the web than in person. Those who engage in sexual negotiations are also more likely to use condoms for anal intercourse $[17,18]$ but, or the other hand, some MSM may be using the internet to seek for unprotected sex [19].

Pleasure plays a central role in motivating human sexual experience $[20,21]$. Consequently, any artifice that may interfere with the pleasures of sex is likely to be avoided. This is particularly true of latex condoms, the cornerstone of current international efforts to prevent the spread of HIV and other sexually transmitted infections, since condoms interpose a mechanical barrier between sex partners, limit physical contact, reduce tactile sensation, and attenuate heat transduction, all of which may reduce sexual pleasure [4]. This reduction in pleasure is one of the main reasons people cite for eschewing condom use [22].

Also, sexual pleasure has been identified as an important consideration in decision-making surrounding condom use. Calabrese et al. [23] examined the impact of perceived pleasure loss associated with condom use, on recent history of insertive and receptive unprotected anal intercourse among MSM, and concluded that men who had engaged in both positions, with and without condoms, perceived a greater pleasure loss associated with condoms during anal intercourse in the insertive versus receptive position. Pleasure loss was associated with condom use, but it may be a key deterrent for their use in either sex position among MSM.

However, there is a lack of data from Portugal to determine if it differs from these patterns, and the lack of such data hinders HIV prevention efforts specifically targeted at MSM. While we have some indicators of sexual risk behavior and its predictors, little has been published on the importance of sexual pleasure and the contexts of sexual interaction among MSM. The purpose of this study is to assess the types of sexual behaviors among MSM, with and without a condom use, and to assess the predictive relationship between sexual pleasure and risky sexual practices.

\section{Methods}

\section{Participants}

A total of 304 MSM participated in this research. The inclusion criteria for participation in the study were: (1) being MSM, (2) being over 18 years of age, (3) being Portuguese (either national or legal resident/citizen) and living in Portugal, and (4) willingness to participate voluntarily in the study after knowing its objectives. Participants were recruited through two sampling methods: (1) Informal social networks. The eligible MSM who agreed to participate were asked to refer their friends to participate in the study; and (2) the internet. The local researcher distributed announcements via local gay websites to reach potential participants. The study was conducted from January 2013 to June 2013.

\section{Measures}

Demographic characteristics: Data on participants' age, education level, marital status, sexual orientation, and HIV status were collected. For the purpose of data analysis, education and marital status were grouped into several categories.

Sexual pleasure: Sexual pleasure was operationalized using one measure with 8 items created for this study. Participants were instructed to respond to the items on a 5 -point Likert-type scale $(1=$ no pleasure at all; $5=$ a lot of pleasure). The 8 items comprised the ideal scenario of having certain sexual activities, and asked participants which activity would give them the most sexual pleasure. The 8 items were: 1 . What level of sexual pleasure would you feel by having anal receptive sex (to be penetrated) without a condom? 2. What level of sexual pleasure would you feel by having anal receptive sex (to be penetrated) with a condom? 3. What level of sexual pleasure would you feel by having anal insertive sex (to penetrate) without a condom? 4. What level of sexual pleasure would you feel by having anal insertive sex (to penetrate) with a condom? 5 . What level of sexual pleasure would you feel by ejaculating inside a man's rectum without a condom? 6. What level of sexual pleasure would you feel by ejaculating inside a man's rectum with a condom? 7 . What level of sexual pleasure would you feel by having a man ejaculate inside your rectum without a condom? and 8 . What level of sexual pleasure would you feel by having a man ejaculate inside your rectum with a condom? Reliability analysis was $\operatorname{good}(\alpha=0.76)$.

Sexual practices: Participants were asked to recall their sexual experiences and their sexual behaviors over the last two months. Information was collected regarding: (1) receptive anal sex (how many times he was penetrated by a man with and without a condom, and how many men penetrated him with and without a condom); (2) insertive anal sex (how many times he penetrated a man with and without a condom, and how many men he penetrated with and without a condom); (3) receptive and insertive oral sex (how many times and how many men he had oral sex with, with and without a condom, being receptive or insertive).

\section{Analyses}

Analysis was carried out using SPSS version 21. Variables were analyzed using simple frequency and percentage. Simple logistic regression was carried out on condom use to predict condom less 
Citation: Pereira H (2014) Condom Use and HIV-Related Behaviors in Portuguese Men who have Sex with Men: A Study of Sexual Behavior and Sexual Pleasure. J AIDS Clin Res 5: 294. doi:10.4172/2155-6113.1000294

Page 3 of 5

intercourse (dependent variable) with sexual pleasure (independent variable), significant at $\mathrm{p}<0.05$. T-test was used to compare differences in the mean frequency of condom use during various sexual situations. All tests were two-tailed.

\begin{tabular}{|l|c|c|}
\hline Self-identification & $\mathrm{n}$ & $\%$ \\
$\quad$ Gay & & \\
Bisexual & 213 & 70.06 \\
Marital status & 91 & 29.94 \\
Single & 180 & 59.21 \\
Emotional commitment & 58 & 19.08 \\
Divorced & 16 & 5.26 \\
Married to a man & 7 & 2.30 \\
Married to a woman & 12 & 3.95 \\
Civil Union to a man & 23 & 7.57 \\
Civil union to a woman & 8 & 2.63 \\
Education & 27 & \\
Up to 9 years of school & 73 & 8.88 \\
Up to 12 years of school & 79 & 24.01 \\
University/college attendance & 56 & 25.98 \\
Pre-graduate degree & 69 & 18.43 \\
Post-graduate degree & & 22.70 \\
HIV status & 203 & 66.77 \\
Negative & 22 & 7.24 \\
Positive & 79 & 25.99 \\
Doesnot know & & \\
\hline
\end{tabular}

Mean age $32.30, \mathrm{SD}=11.28$, median $=31$

Table 1: Demographic characteristics $(n=304)$.

\section{Ethical approval}

This study was approved by the scientific and ethical committees of the Research Unit of Health and Psychology (UIPES-ISPA, Institute of Applied Psychology in Portugal).

\section{Results}

\section{Demographic data}

Demographic data (Table 1) show that the sample is highly differentiated and educated, the majority of men are single and selfidentify as gay. Only $7.2 \%$ of participant's state being HIV positive, approximately $26 \%$ report not knowing.

\section{Sexual practices}

Table 2 shows the results for the sexual practices within the last two months, using or not using a condom. Significant differences were found between having sex with or without a condom for receptive anal sex (more men penetrated the participants with a condom, $\mathrm{p}=0.036$ ), for insertive anal sex (more participants penetrated another man with a condom, $\mathrm{p}=0.012$ ), and for oral sex (all differences indicate that a condom is much less used for this type of sex, $\mathrm{p}<0.001$ ).

\section{Pleasure}

As it can be seen on Table 3, all participants indicated they would feel

\begin{tabular}{|c|c|c|c|c|c|}
\hline Sexual practices within the last two months & With or Without a condom & Mean & Std. Deviation & $\mathbf{t}$ & p-value \\
\hline \multirow{2}{*}{ How many times were you penetrated } & With a condom & 2.89 & 6.78 & -.03 & .978 \\
\hline & Without a condom & 2.90 & 8.71 & & \\
\hline \multirow{2}{*}{ How many men penetrated you } & With a condom & 1.36 & 3.70 & 2.10 & $.036^{*}$ \\
\hline & Without a condom & .72 & 3.46 & & \\
\hline \multirow{2}{*}{ How many times did you penetrate } & With a condom & 3.69 & 9.60 & .41 & .680 \\
\hline & Without a condom & 3.36 & 9.13 & & \\
\hline \multirow{2}{*}{ How many men did you penetrate } & With a condom & 2.12 & 7.69 & 2.51 & $.012^{*}$ \\
\hline & Without a condom & 0.84 & 3.57 & & \\
\hline \multirow{2}{*}{ How many times did you perform oral sex } & With a condom & 1.38 & 6.60 & -8.47 & $<0.001^{*}$ \\
\hline & Without a condom & 8.73 & 12.95 & & \\
\hline \multirow{2}{*}{ How many men did you perform oral sex to } & With a condom & .65 & 4.02 & -4.86 & $<0.001^{*}$ \\
\hline & Without a condom & 3.23 & 7.88 & & \\
\hline \multirow{2}{*}{$\begin{array}{l}\text { How many times did someone perform oral sex } \\
\text { on you }\end{array}$} & With a condom & .85 & 4.54 & -8.73 & $<0.001^{*}$ \\
\hline & Without a condom & 9.01 & 14.98 & & \\
\hline \multirow{2}{*}{ How many men performed oral sex on you } & With a condom & .71 & 4.29 & -4.26 & $<0.001^{*}$ \\
\hline & Without a condom & 3.41 & 9.73 & & \\
\hline
\end{tabular}

${ }^{*} p<0.05$

Table 2: Results of condom use within the last two months among men having sex with men in Portugal $(n=304)$.

\begin{tabular}{|c|c|c|c|c|c|}
\hline Levels of pleasure felt (1-5) & With or without a condom & Mean level of pleasure & Std. Deviation & $\mathbf{t}$ & p-value \\
\hline \multirow{2}{*}{ Having receptive anal sex } & Without a condom & 3.72 & 1.48 & 2.80 & $.005^{*}$ \\
\hline & With a condom & 3.39 & 1.25 & & \\
\hline \multirow{2}{*}{ Having Insertive anal sex } & Without a condom & 3.88 & 1.43 & 4.47 & $<0.001^{*}$ \\
\hline & With a condom & 3.38 & 1.18 & & \\
\hline \multirow{2}{*}{ To ejaculate inside the partner's rectum } & Without a condom & 3.82 & 1.49 & 4.69 & $<0.001^{*}$ \\
\hline & With a condom & 3.27 & 1.25 & & \\
\hline \multirow{2}{*}{$\begin{array}{l}\text { Having your partner ejaculate inside } \\
\text { your rectum }\end{array}$} & Without a condom & 3.24 & 1.66 & 1.69 & .091 \\
\hline & With a condom & 3.02 & 1.32 & & \\
\hline
\end{tabular}

${ }^{*} \mathrm{p}<0.05$

Table 3: Results for levels of pleasure felt if not using a condom. 


\begin{tabular}{|l|c|}
\hline Types of pleasure & $\boldsymbol{\beta}$ \\
\hline Having receptive anal sex without a condom & $.255^{*}$ \\
\hline Having receptive anal sex with a condom & -.118 \\
\hline Having insertive anal sex without a condom & .144 \\
\hline Having insertive anal sex with a condom & -.038 \\
\hline To ejaculate inside the partner's rectum without a condom & $-.209^{*}$ \\
\hline To ejaculate inside the partner's rectum with a condom & $.192^{*}$ \\
\hline Having your partner ejaculate inside your rectum without a condom & .082 \\
\hline Having your partner ejaculate inside your rectum with a condom & -.017 \\
\hline *<0.05 & \\
\hline
\end{tabular}

Table 4: Results for Model 1: Pleasure as a predictor of how many times a man was penetrated without a condom.

\begin{tabular}{|l|c|}
\hline Types of pleasure & $\boldsymbol{\beta}$ \\
\hline Having receptive anal sex without a condom & -.026 \\
\hline Having receptive anal sex with a condom & .039 \\
\hline Having insertive anal sex without a condom & $.291^{*}$ \\
\hline Having insertive anal sex with a condom & -.166 \\
\hline To ejaculate inside the partner's rectum without a condom & -.033 \\
\hline To ejaculate inside the partner's rectum with a condom & .167 \\
\hline Having your partner ejaculate inside your rectum without a condom & -.092 \\
\hline Having your partner ejaculate inside your rectum with a condom & -.030 \\
\hline$*<0.05$ & \\
\hline
\end{tabular}

Table 5: Results for Model 2 - Pleasure as a predictor of how many times a man penetrated another man without a condom.

higher levels of sexual pleasure if they were not using a condom during their sexual interaction, and all differences are statistically significant except for "having your partner ejaculate inside your rectum".

\section{Pleasure as a predictor of HIV-related behaviors}

For receptive anal sex, univariate linear regression indicates that scoring higher regarding levels of sexual pleasure on "Having receptive anal sex without a condom" and "To ejaculate inside the partner's rectum without a condom" is a predictor of the number of times a man was penetrated without a condom $(\mathrm{R} 2=.084 ; \mathrm{p}<0.005)$ (Table 4$)$.

For insertive anal sex, linear regression indicates that scoring higher regarding levels of sexual pleasure on "Having insertive anal sex without a condom" is a predictor of how many times a man penetrated another man without a condom $(\mathrm{R} 2=.084$; $\mathrm{p}<0.005)$ (Table 5).

\section{Discussion}

Despite a significant increase in HIV testing and treatment, the percentage of HIV infection in MSM has increased over the last 10 years in Portugal. The current study examined the frequency and associations between sexual risk behaviors and sexual pleasure among a sample of Portuguese MSM, since not many studies address this association, perhaps because it seems too obvious. Nevertheless, the disproportion of new HIV infections among MSM requires us to examine the fundamental issues of sexual experience assuming that there are no simple truths involved in the determination of sexual risk behavior.

Before the AIDS epidemic, MSM had spent the previous decades behaving in post-liberation sexuality, and all sex was, by today's definition, unsafe sex, since virtually no one used condoms with the purpose of preventing HIV transmissions [15]. In this sense, the "obligation" to use condoms was seen as an imposed necessity with associated costs, namely, the loss of sexual pleasure. Yet, since the emergence of HIV, sexual risk-reduction intervention and prevention programs have promoted that 'condoms equal safer sex', a message with a particular focus on the preventive aspects of condoms, and despite the pervasiveness of this message, research has found that most MSM fail to use condoms consistently [24].

Overall, the results of this study show that MSM have more sexual/ sensory pleasure associations to condomless sex, suggesting that interventions highlighting the sexual/sensory aspects of condoms might be an important component to increase condom use among MSM. It also corroborates the idea that men will behave sexually more accordingly to the pleasure they seek than the information they have regarding HIV exposure. These results may be influenced by the fact that there are many committed gay couples, who practice condomless safe sex, perhaps because both partners are HIV-negative and they trust each other enough to sustain such an arrangement.

The results of the few studies conducted with Portuguese MSM [25] indicate that cultural variables may also be important in understanding MSM responses to HIV/AIDS and its influence on the attribution of importance to sexual pleasure, since cultures transmit values and expectations that influence the sexual behaviors of their members. It is critical that we understand cultural influences on behaviors relevant to HIV risk to reduce the further spreading of HIV among MSM. Greater insight on the influence of pleasure will enrich theoretical models of risk, which have tended to overlook social and cultural dynamics.

According to a report from the Commissioner for Human Rights from the Council of Europe [26], Portuguese people are not comfortable about having a homosexual person as neighbor, and are against samesex marriage and same-sex parenting. Consequently, the identity development of MSM individuals is restricted by these negative societal attitudes, which generally results in the internalization of the stigma associated with their sexual and/or gender identity [27], which has been shown to be associated with risky sexual behaviors [28].

These findings demonstrate how personal priorities, values and meanings are central to the negotiation of risk in sexual relationships, in which biomedical understandings of risk - especially those based on the biological markers of viral load detection - are balanced against a broader set of social expectations, desires, and sensation seeking [14]. Negotiations between the desire for physical pleasure and a dislike of condoms seem to be given as justifications for unprotected sex between MSM.

Portuguese (MSM) erotic culture, and stigma/discrimination, pressure to omit or concede their status, along with the added security of an undetectable viral load due to current adherence to medication all may lead to the rationalization of how risk is produced and Portuguese MSM may feel more likely to defend unprotected sex as not only being more pleasurable but also as signifying a return to an intimate relationship and to a sense of 'normality' weakened by the public health messages that view sexual risk through a biomedical lens only and deny the significance and meaning given to sex and condoms within a relationship and the unquestionable force of love, pleasure and intimacy [29].

Perceptions of low sexual control have been frequently used as justification for unprotected anal sex, in studies with MSM, but failed to operationalize sexual pleasure as the main motivator for such exposure. Discrimination toward homosexual behavior is a context of risk and oppression, which have been found to be strong predictors of HIV risk among MSM men, but the contribution of this study forces us to admit that perhaps men really seek what they assess as more pleasurable, even if the associated costs (including HIV infection) are present. Therefore, pleasure needs to be prioritized in the development of condoms and other sexual safety measures as well as in the promotion of their use. 
Citation: Pereira H (2014) Condom Use and HIV-Related Behaviors in Portuguese Men who have Sex with Men: A Study of Sexual Behavior and Sexual Pleasure. J AIDS Clin Res 5: 294. doi:10.4172/2155-6113.1000294

\section{References}

1. Departamento de Doenças Infecciosas (DDI) (2012). Infeção VIH/SIDA: a situação em Portugal a 31 de dezembro de 2011. Lisboa: INSA.

2. UNAIDS (2013) UNAIDS Report on the global AIDS epidemic. WHO Library Cataloguing in Publication Data.

3. Lorimer K, Kidd L, Lawrence M, McPherson K, Cayless S, et al. (2013) Systematic review of reviews of behavioural HIV prevention interventions among men who have sex with men. AIDS Care 25: 133-150.

4. Randolph ME, Pinkerton SD, Bogart LM, Cecil H, Abramson PR (2007) Sexual pleasure and condom use. Arch Sex Behav 36: 844-848.

5. Berhan Y, Berhan A (2013) Meta-analysis on risky sexual behaviour of men: consistent findings from different parts of the world. AIDS Care 25: 151-159.

6. Hearst N, Chen S (2003) Condoms for AIDS prevention in the developing world: A review of the scientific literature. University of California.

7. Pinkerton SD, Abramson PR (1997) Effectiveness of condoms in preventing HIV transmission. Soc Sci Med 44: 1303-1312.

8. Holmes KK, Levine R, Weaver M (2004) Effectiveness of condoms in preventing sexually transmitted infections. Bull World Health Organ 82: 454-461.

9. Leobon A, Velter A, Engler K, Drouin MC, Otis J (2011) A relative profile of HIVnegative users of French websites for men seeking men and predictors of their regular risk taking: a comparison with HIV-positive users. AIDS Care 23: 25-34.

10. Rouwenhorst E, Mallitt KA, Prestage G (2012) Gay men's use of condoms with casual partners depends on the extent of their prior acquaintance. AIDS Behav 16: $1589-1596$

11. Hurley M1, Prestage G (2009) Intensive sex partying amongst gay men in Sydney. Cult Health Sex 11: 597-610.

12. Bauermeister JA, Carballo-Diéguez A, Ventuneac A, Dolezal C (2009) Assessing motivations to engage in intentional condomless anal intercourse in HIV risk contexts ("Bareback Sex") among men who have sex with men. AIDS Educ Prev 21: 156-168.

13. Carballo-Diéguez A, Ventuneac A, Dowsett GW, Balan I, Bauermeister J, et al (2011) Sexual pleasure and intimacy among men who engage in "bareback sex". AIDS Behav 15 Suppl 1: S57-65.

14. Kelly C, Lohan M, Alderdice F, Spence D (2011) Negotiation of risk in sexual relationships and reproductive decision-making amongst HIV sero-different couples. Cult Health Sex 13: 815-827.

15. Blechner MJ (2002) Intimacy, Pleasure, Risk, and Safety: Discussion of Cheuvront's "High-Risk Sexual Behavior in the Treatment of HIV-Negative Patients. Journal of Gay \& Lesbian Psychotherapy 6: 27-33.
16. Hoff CC, Chakravarty D, Beougher SC, Neilands TB, Darbes LA (2012) Relationship characteristics associated with sexual risk behavior among MSM in committed relationships. AIDS Patient Care STDS 26: 738-745.

17. Carballo-Diéguez A, Miner M, Dolezal C, Rosser BR, Jacoby S (2006) Sexual negotiation, HIV-status disclosure, and sexual risk behavior among Latino men who use the internet to seek sex with other men. Arch Sex Behav 35: 473-481.

18. Nodin N, Valera P, Ventuneac A, Maynard E, Carballo-Diéguez A (2011) The Internet profiles of men who have sex with men within bareback websites. Cult Health Sex 13: 1015-1029.

19. da Silva LA, Iriart JA (2012) The meanings and practices of barebacking among Brazilian internet users. Sociol Health IIIn 34: 651-664.

20. Abramson PR, Pinkerton SD (2002) With pleasure: Thoughts on the nature of human sexuality. Oxford University Press, New York.

21. Pinkerton S, Cecil H, Bogart L, Abramson P (2003) The pleasures of sex: An empirical investigation. Cognition and Emotion 17: 341-353.

22. Norton TR, Bogart LM, Cecil H, Pinkerton SD (2005) Primacy of affect over cognition in determining adultmen's condom use behavior: A review. Journal of Applied Social Psychology 35: 2493-2534.

23. Calabrese SK, Reisen CA, Zea MC, Poppen PJ, Bianchi FT (2012) The pleasure principle: the effect of perceived pleasure loss associated with condoms on unprotected anal intercourse among immigrant Latino men who have sex with men. AIDS Patient Care STDS 26: 430-435.

24. Scott-Sheldon LA, Marsh KL, Johnson BT, Glasford DE (2006) Condoms + pleasure $=$ safer sex ? A missing addend in the safer sex message. AIDS Care 18: $750-754$

25. Pereira H (2007) Determinantes do risco e implicações para a saúde nas práticas sexuais de homens que têm sexo com homens. Análise Psicológica 3: 517-527.

26. Commissioner for Human Rights (2011) Discrimination on grounds of sexua orientation and gender identity in Europe. Council of Europe, Strasbourg, France.

27. Costa PA, Pereira H, Leal I (2013) Internalized Homonegativity, Disclosure, and Acceptance of Sexual Orientation in a Sample of Portuguese Gay and Bisexual Men, and Lesbian and Bisexual Women. Journal of Bisexuality 13: 229-244.

28. Dew BJ, Chaney MP (2005) The relationship among sexual compulsivity, internalized homophobia, and HIV at-risk sexual behavior in gay and bisexual users of Internet chat rooms. Sexual Addiction \& Compulsivity: The Journal of Treatment \& Prevention 12: 259-273.

29. Dowsett GW (2003) Some considerations on sexuality and gender in the context of AIDS. Reprod Health Matters 11: 21-29. 